\title{
Online Social Trust in Government: Analysis of Government Policy During the Covid-19 Pandemic
}

\author{
Tawakkal Baharuddin ${ }^{1}$, Hasse Jubba ${ }^{2}$, Achmad Nurmandi $^{3}$, Zuly Qodir ${ }^{4}$ \\ \{tawakkal.b.pasca18@mail.umy.ac.id¹, hasse@umy.ac.id², nurmandi_achmad@umy.ac.id ${ }^{3}$, \\ zuliqodir@umy.ac.id $\left.{ }^{4}\right\}$
}

Doctor of Political Islam-Political Science, Universitas Muhammadiyah Yogyakarta ${ }^{1,2,3,4}$

\begin{abstract}
The COVID-19 pandemic has caused problems in various sectors such as health, economy, and many aspects of social life. During this situation, the Indonesian government has implemented multiple policies to suppress the spread of the coronavirus called Large-Scale Social Restrictions (PSBB) and the Community Activities Restrictions Enforcement (PPKM). The purpose of this study is to analyze the level of online social trust in the government regarding activity restriction policies during the COVID-19 pandemic period in Indonesia. The research method used was quantitative with descriptive content analysis. The data sources were literature study, documentation, and Twitter. The analytical tool used was Nvivo 12 Plus. The results indicated that the activity restriction policies (PSBB and PPKM) were still less than optimal and even lowered social trust. The dominant aspects were the government's attitude and behavior in implementing its policies. The low public trust also affected the community's behavior, attitudes, and willingness to actively and voluntarily. This research contributes to evaluate the government's policies during the crisis period due to the COVID-19 pandemic. This study is expected to influence the effectiveness of public policies in the future and positively impact social acceptance of policies and bridging social capital.
\end{abstract}

Keywords: Social trust; trust in institutions; government policy; COVID-19; bridging social capital

\section{Introduction}

The COVID-19 pandemic has become a global problem today and has affected many aspects of human life, including health, education, economic, social, and political issues in Indonesia (Leach et al. 2021; Machmud et al. 2020; Abdullah 2020; Qodir et al. 2020). Based on these impacts, the government has made various ways through policies during the pandemic. In the beginning, several government policies limited certain activities known as Large-Scale Social Restrictions (PSBB). PSBB is a policy to reduce the cases in public spaces. PSBB includes the closure of schools, workplaces, restrictions on religious activities, and other public places or facilities. However, these policies were less optimal and have received various responses and criticisms (Baharuddin et al., 2021).

Therefore, the Indonesian government then responded by enacting several other policies. 
These policies are known by various terms, such as the Community Activities Restrictions Enforcement (PPKM) in Java and Bali to limit community activities in red or dark zones. Then, the government implemented another policy, called MICRO PPKM. The rules that apply follow the zone labels of each environment in each region. After implementing the policy, the following policy extended PPKM Micro followed by other policies such as Emergency PPKM and PPKM Level 3-4. However, these policies still reap various public responses in Indonesia, including in the public space and digital spaces or social media (Allen 2021). As long as activity restrictions are going, social media will always express their users' opinions and disseminate information and education (Cinelli et al. 2020; Suratnoaji, Nurhadi, and Arianto 2020).

So far, studies analyzing policies related to activity restrictions only assess the level of social trust, especially limited online social trust. However, some trends from previous studies can be mapped. First, the COVID-19 pandemic has affected the government's response in anticipating the cases by implementing a policy of limiting activities (Suryahadi, Al Izzati, and Suryadarma 2020; Syuhada et al. 2021). Second, the pandemic also affects social trust and social capital on policy effectiveness and acceptance (Baharuddin et al., 2021; Bargain and Aminjonov 2020). Third, maintaining the stability of public confidence during the crisis due to the pandemic is a crucial aspect to reduce cases and, at the same time, contribute to bridging social capital (Pitas and Ehmer 2020; Wong and Kohler 2020).

This paper attempts to fill previous studies' gaps by conducting an analytical approach in online social networks such as Twitter, specifically related to social restriction policy issues during the COVID-19 pandemic in Indonesia. Therefore, this paper can formulate two questions: (a) What is the level of online social trust in government policies related to activity restrictions during the COVID-19 pandemic period in Indonesia? (b) What factors affect the level of online social trust in activity restriction policies in Indonesia? The answers to these two questions allow the finding of solutions to improve the social situation and become material for the government's evaluation which is closely related to decision making and policy implementation.

This study used a quantitative approach with descriptive content analysis. The research subjects were Twitter users. The object of research was seen from Twitter users' involvement in policy issues related to activity restrictions. The data was obtained from Twitter, focusing on keywords such as COVID-19 Indonesia, PSBB (Large-Scale Social Restrictions), and PPKM (Community Activities Restrictions Enforcement). The data retrieval used Ncapture and was analyzed using Nvivo 12 Plus. Nvivo 12 plus software is an analysis tool to display data in text and images through the data coding process. The coding results on the data were then visualized, described, and analyzed to answer research questions.

\section{Findings and Discussion}

\subsection{Online Social Trust against Activity Restriction Policy}

The policy of limiting activities has been carried out since the beginning of 2020, known as Large-Scale Social Restrictions (PSBB). PSBB attempted to stop people's productive activities by considering the number of infected cases to be low and hoping to reduce the number of cases spreading in various regions in Indonesia. Entering 2021, the Indonesian government issued a similar policy called Community Activities Restrictions Enforcement (PPKM). PPKM is a policy identical to PSBB, which limits community activities at various 
vulnerable zones. During the pandemic, the PSBB and PPKM policies received responses from the public, especially Twitter users.

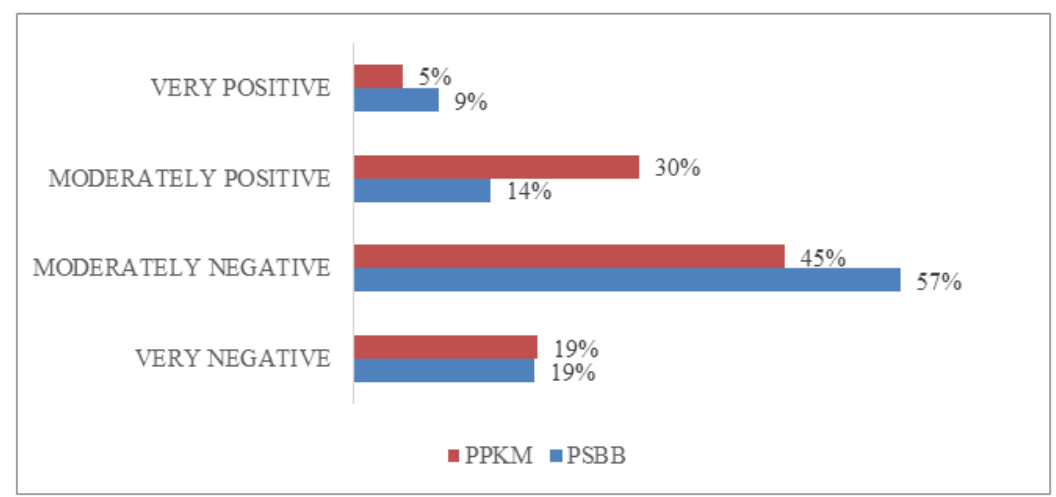

Fig. 1. Online Social Trust regarding Activity Restriction Policy

Figure 1 shows that the government's policy limiting community activities from 2020 to 2021 by imposing PSBB and PPKM affects the level of social trust during the COVID-19 pandemic. Low trust causes the policies taken by the government not to run optimally. This low trust makes the community less cooperative and participatory in involving themselves and their communities to work together to reduce COVID-19 cases and their spread.

Low social trust in online social networks needs to be a concern for the government in formulating policies that maintain public trust, especially during the transition period. The social trust shown in the social community will positively impact bridging social capital and, at the same time, influence the community's attitude and acceptance. Social capital provides benefits during critical periods. High social capital responds more efficiently than those with low social capital (Pitas and Ehmer 2020; Baharuddin et al. 2021; Makridis and Wu 2021).

\subsection{Factors Affecting Online Social Trust Levels}

Previously, social restriction policies such as PSBB and PPKM negatively affected low social trust. Furthermore, this study outlines several factors that underlie the low online social trust in implementing social restrictions during the COVID-19 pandemic in Indonesia.

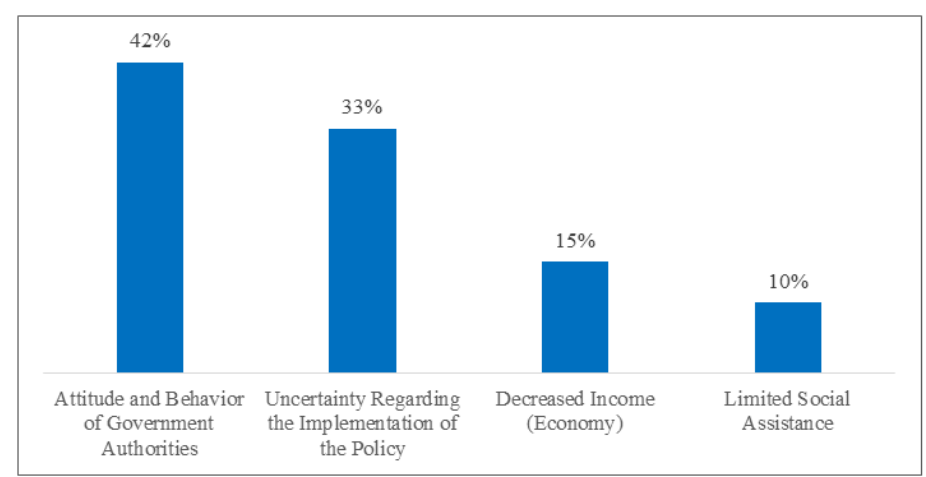

Fig. 2. Factors Affecting Low Social Trust Online Related to Activity Restriction Policies 
Figure 2 shows that several factors influence low online social trust in activity restriction policies during the COVID-19 pandemic. First, the behavior and attitude of the government authorities in enforcing and carrying out activity restriction policies through the PSBB and PPKM policies are still less than optimal. Second, the government's uncertainty in implementing policies makes the public confused because they change and impose similar new policies with different terms. Third, restrictions on PSBB activities to PPKM are considered to hamper people's productivity in earning income and influence social and economic life. Fourth, during the activity restrictions, the affected communities did not receive social assistance equitably and fairly.

Based on the findings above, the Indonesian government has made various efforts to reduce infection cases during the COVID-19 pandemic. However, the policies tend to be considered less than optimal, thus affecting low social trust. Low social trust also decreases public interest, attitude, and willingness to comply with applicable policies. Therefore, the government must evaluate by enacting policies that focus on aspects of social trust. High social trust positively contributes to the social community and can influence people's behavior to be actively involved voluntarily (Baharuddin et al., 2021; Lachapelle et al., 2021). Trust in institutional organizations facilitates acceptance of policies enforced during pandemic period (Di Marco, Hichy, and Sciacca 2021).

Trust is seen as an important aspect to facilitate good governance. This claim has been the inspiration that emerged during the coronavirus pandemic (Devine et al. 2021). Trust has elements that need to be considered such as socio-cultural characteristics, individual personalities, and sources of information. These conceptualizations of beliefs tend to operate simultaneously and influence each other at several levels (Chryssochoidis, Strada, and Krystallis 2009). During the pandemic, many countries have responded to the spread of COVID-19 with a variety of policies and related factors, namely about social trust, where social trust is an aspect that determines the government's response and capacity in the pandemic stage (Toshkov, Carroll, and Yesilkagit 2021).

\section{Conclusion}

The government has imposed a policy of limiting activities called Large-Scale Social Restrictions (PSBB) and Community Activities Restrictions Enforcement (PPKM) to reduce cases in various regions of Indonesia. However, these policies have been less than optimal and tend to decline social trust in social communities, especially online social networks. Low social trust also impacts behavior, willingness, and community participation in supporting government policies during the pandemic. The most dominant aspect is the government's behavior and attitude in implementing these policies. This research explained that the government must evaluate each policy while at the same time paying attention to and maintaining social trust. This study is expected to influence the effectiveness of public policies in the future and positively impact social acceptance of policies and bridging social capital.

\section{Reference}

[1] Abdullah, Irwan. 2020. "COVID-19: Threat and Fear in Indonesia." Psychological Trauma: Theory, Research, Practice, and Policy 12(5):488-90.

[2] Allen, Sydney. 2021. "Indonesia Faces Criticism for Lack of Financial Support amid 
Lockdowns."

Globalvoices.Org.

Retrieved

(https:/globalvoices.org/2021/07/28/indonesia-faces-criticism-for-lack-of-financialsupport-amid-lockdowns/).

[3] Azhari, Budi and Iwan Fajri. 2021. "Distance Learning during the COVID-19 Pandemic: School Closure in Indonesia." International Journal of Mathematical Education in Science and Technology.

[4] Baharuddin, Tawakkal, Sjafri Sairin, Hasse Jubba, Zuly Qodir, Achmad Nurmandi, and Mega Hidayati. 2021. "Social Capital and Social Trust: The State' s Response in Facing the Spread of COVID-19 in Indonesia." Sociology and Technoscience 11(2):23-47.

[5] Bargain, Olivier and Ulugbek Aminjonov. 2020. "Trust and Compliance to Public Health Policies in Times of COVID-19." Journal of Public Economics 192:104316.

[6] Chryssochoidis, George, Anna Strada, and Athanasios Krystallis. 2009. "Public Trust in Institutions and Information Sources Regarding Risk Management and Communication: Towards Integrating Extant Knowledge.” Journal of Risk Research 12(2):137-85.

[7] Cinelli, Matteo, Walter Quattrociocchi, Alessandro Galeazzi, Carlo Michele Valensise, Emanuele Brugnoli, Ana Lucia Schmidt, Paola Zola, Fabiana Zollo, and Antonio Scala. 2020. "The COVID-19 Social Media Infodemic." Scientific Reports 10(1):1-18.

[8] Devine, Daniel, Jennifer Gaskell, Will Jennings, and Gerry Stoker. 2021. "Trust and the Coronavirus Pandemic: What Are the Consequences of and for Trust? An Early Review of the Literature." Political Studies Review 19(2):274-85.

[9] Di Marco, Graziella, Zira Hichy, and Federica Sciacca. 2021. "Attitudes towards Lockdown, Trust in Institutions, and Civic Engagement: A Study on Sicilians during the Coronavirus Lockdown.” Journal of Public Affairs e2739.

[10] Lachapelle, Erick, Thomas Bergeron, Richard Nadeau, Jean François Daoust, Ruth Dassonneville, and Éric Bélanger. 2021. "Citizens' Willingness to Support New Taxes for COVID-19 Measures and the Role of Trust." Politics and Policy 49(3):534-65.

[11] Leach, Melissa, Hayley MacGregor, Ian Scoones, and Annie Wilkinson. 2021. "PostPandemic Transformations: How and Why COVID-19 Requires Us to Rethink Development." World Development 138:105233.

[12] Machmud, Muslimin, Abdullah Masmuh, Chairun Nasirin, Salahudin, Tawakkal Baharuddin, and Andi Ernie Zaenab Musma. 2020. "Artificial Intelligence In The Public Health Sector: The Use Of Telemedicine In Indonesia During Covid-19." Palarch, Journal Of Archaeology Of Egypt/Egyptology 17(7):10106-18.

[13] Makridis, Christos A. and Cary Wu. 2021. "How Social Capital Helps Communities Weather the COVID-19 Pandemic." PLoS ONE 16(1):1-18.

[14] Pitas, Nicholas and Colin Ehmer. 2020. "Social Capital in the Response to COVID19." American Journal of Health Promotion 34(8):942-44.

[15] Qodir, Zuly, Ghina Nabilah Effendi, Hasse Jubba, Achmad Nurmandi, and Mega Hidayati. 2020. "Covid-19 and Chaos in Indonesia Social-Political." International Research Association for Talent Development and Excellence 12(1):4629-42.

[16] Suratnoaji, Catur, Nurhadi, and Irwan Dwi Arianto. 2020. "Public Opinion on Lockdown (PSBB) Policy in Overcoming Covid-19 Pandemic in Indonesia: Analysis Based on Big Data Twitter." Asian Journal for Public Opinion Research 8(3):393-406. 
[17] Suryahadi, Asep, Ridho Al Izzati, and Daniel Suryadarma. 2020. "Estimating the Impact of Covid-19 on Poverty in Indonesia." Bulletin of Indonesian Economic Studies 56(2):175-92.

[18] Syuhada, Khreshna, Aqilah Wibisono, Arief Hakim, and Fida Addini. 2021. "Covid-19 Risk Data during Lockdown-like Policy in Indonesia." Data in Brief 35:106801.

[19] Toshkov, Dimiter, Brendan Carroll, and Kutsal Yesilkagit. 2021. "Government Capacity, Societal Trust or Party Preferences: What Accounts for the Variety of National Policy Responses to the COVID-19 Pandemic in Europe?" Journal of European Public Policy 1-20.

[20] Wong, Anna S. Y., and Jillian C. Kohler. 2020. "Social Capital and Public Health: Responding to the COVID-19 Pandemic." Globalization and Health 16(1):1-4. 